\title{
Optimization of the formulation and post-treatment of stainless steel for rapid manufacturing
}

\author{
G. Vaneetveld ${ }^{a, *}$, A.-M. Clarinual ${ }^{b}$, T. Dormal ${ }^{b}$, J.-C. Noben $^{c}$, J. Lecomte-Beckers ${ }^{d}$ \\ a Thixo Unit, University of Liège, 4, Boulevard de Colonster, Sart Tilman, 4000 Liège, Belgium \\ b CRIF-WTCM Rapid Manufacturing Departement, 4102 Seraing, Belgium \\ c Metal Inject SA, 4140 Sprimont, Belgium \\ d MMS (IMGC, Bât. B52), University of Liège, 1, Chemin des Cheureuils, Sart Tilman, 4000 Liège, Belgium
}

\section{A R T I C L E I N F O}

Article history:

Received 16 June 2005

Received in revised form

18 April 2007

Accepted 11 May 2007

Keywords:

Bimodal distribution

Rapid manufacturing

Grain size

Powder metallurgy

Porosity

\begin{abstract}
A B S T R A C T
Rapid prototyping process called Optoform shapes functional parts from a photocurable paste. This paste contains metal powder, resin, UV photoinitiator and wetting agent. After processing on the Optoform machine, a post-treatment is applied (debinding + sintering). During the post-treatment, the residual carbon coming from the resin modifies the composition of the metal and its melting point. This modification affects densification mechanisms, which leads to a residual porosity that lowers mechanical characteristics. We will present theoretical consideration leading to the optimization of the formulation. To improve the process, bimodal powder is used and thermal treatment is adapted.
\end{abstract}

(c) 2007 Elsevier B.V. All rights reserved.

\section{Introduction}

Starting from a 3D file, a part is built slice by slice from bottom to top, on a plate recovered with a polymer paste which hardens when scanned by a UV laser beam (Chartier et al., 1997; Allanic and Schaeffer, in press; Yukitoshi et al., in press). Such pastes are used for the manufacturing of metallic products by performing an additional thermal treatment. This treatment, comparable to that of parts obtained by a metal injection moulding (MIM) type process, consists, on one hand, in eliminating the organic portion (polymer, thermodegradable additives) of the formed part: the debinding, and on the other hand in sintering the debinded part in order to obtain the desired mechanical characteristics (Dormal, 2000; Clarinval et al., 2003; Clarinval, 2006).
However, current pastes do not allow us to obtain metallic products that present sufficient mechanical characteristics to make functional parts. The main obstacle is the presence of porosity after sintering, which limits mechanical characteristics. This porosity has to be reduced to increase mechanical characteristics (Dormal, 2000; Clarinval et al., 2003; Clarinval, 2006).

The goal of this research is to increase mechanical characteristics of parts formed by Optoform process.

Modifications of the paste have to be done according to rheological properties adapted to the Optoform machine. So, a few parameters have to be changed to control influences on rheological properties. These parameters are the bimodal powder distribution (for better sintering and layering) and the resin/metal proportion (for better debinding and layering).

\footnotetext{
* Corresponding author. Tel.: +32 436159 48; fax: +32 43615959.

E-mail address: g.vaneetveld@ulg.ac.be (G. Vaneetveld). 
Because of these modifications, thermal treatments have to be adapted to improve mechanical characteristics of the parts.

This paper describes influences of modifying parameters of the paste and thermal treatments to obtain good mechanical properties.

\section{General considerations on porosity mechanisms during sintering}

The Optoform process uses a resin, which is source of carbon. This carbon is eliminated by a thermal treatment called debinding. The elimination of the resin, by a sort of pyrolyse during debinding cycle, creates pores in the material. This porosity is reduced by using sintering cycle. The residual carbon influences densification mechanisms by changing the nature of the metal. Consequences are a diminution of the melting point and a modification of the densification mechanisms.

A modelization of the final size of the pores was already treated by Lenel (Lenel, 1980). This modelization requires two assumptions.

During compacting, a gas is entrapped in the pores of the pressed powder, and during the heating to the sintering temperature, the pressure of the gas increases because it is heated at a constant volume. The gas must be of such nature that it neither diffuses through the pressed powder (such as hydrogen) nor reacts with the metal (such as oxygen).

Powder pressed in air contain nitrogen and, if they are heated in hydrogen, also water vapor, which is formed by the reaction of the hydrogen diffusing into the pore with the oxide on the pore wall. Neither nitrogen nor water vapor will diffuse through or react with the metal (Lenel, 1980).

The second assumption is that, due to variation in size of the powder particles, the closed off pores also have a variety of sizes, say from $1 \mu \mathrm{m}$ diameter to $40 \mu \mathrm{m}$ diameter and that the pressure of the gas entrapped in the pores is atmospheric at room temperature. When the pressed powder is heated to sintering temperature, the pressure inside the pores rises. The pressure differential between the entrapped gas and the outside will be the same for all pores, regardless of size (Lenel, 1980).

In our case, for a sintering temperature of inox $316 \mathrm{~L}$ at $1653 \mathrm{~K}\left(1380^{\circ} \mathrm{C}\right)$ and $0.1 \mathrm{MPa}$ with a room temperature of $300 \mathrm{~K}\left(27^{\circ} \mathrm{C}\right)$, the pressure differential will be $(1653 / 300 \times 0.1)-0.1 \mathrm{MPa}$ or approximately $0.45 \mathrm{MPa}$. On the other hand, the shrinkage stress due to the surface tension forces will depend on pore size. For spherical pores, it will be $2 \gamma / r$, where $\gamma$ is the surface tension (about $1.65 \mathrm{~N} / \mathrm{m}$ for a metal at the optimal sintering temperature) and $r$ is the radius of curvature, i.e. the radius of the spherical pore. For a pore $14.6 \mu \mathrm{m}$ in diameter $\left(r=7.3 \times 10^{-6} \mathrm{~m}\right)$, the stress due to the surface tension forces will be $2 \times 1.65 / 7.3 \times 10^{-6}=0.45 \mathrm{MPa}$. For this pore size, the expansion and the contraction stress will therefore just cancel. For pores smaller than $14.6 \mu \mathrm{m}$ the contraction stress will be higher than the expansion stress and the pores will shrink. The pore volume will decrease with the cube of the pore radius. Therefore, the expansion stress will increase and will be inversely proportional to the cube of the pore radius. The contraction stress due to the surface

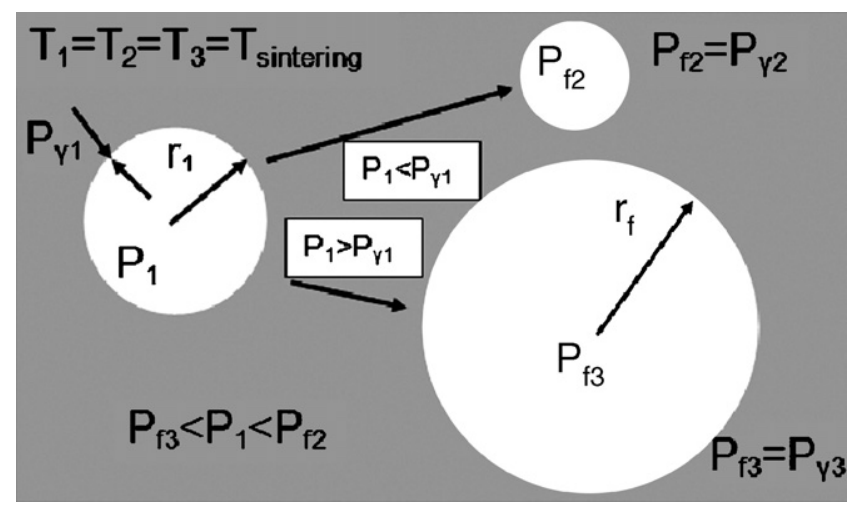

Fig. 1 - Variation of pores size.

tension forces will also increase, but it will be inversely proportional to only the first power of the pore radius. Therefore, a pore size will be reached where the stresses balance. For pores larger than $14.6 \mu \mathrm{m}$, the expansion stress will be higher than the contraction stress and the pores will grow. The expansion stress decreases and will again be inversely proportional to the cube of the pore radius. The contraction stress also decreases, but will be inversely proportional to the first power of the pore radius. Again, a pore size will be reached where the stresses balance (Lenel, 1980). Fig. 1 shows the size variation of the pores. The next formula represents the equilibrium pores size:

$\frac{r_{1}}{r_{f}}=\sqrt{\frac{P_{\gamma 1}}{P_{1}}}$

where $r_{1}, r_{\mathrm{f}}$ represent initial and final radius of the pores; $P_{\gamma 1}$ the initial capillarity pressure of the metal; $P_{1}$ is the gas pressure inside closed off pores at final temperature (sintering) for a spherical porosity with $r_{1}$.

$P_{1}$ depending on the sintering pressure, Fig. 2 shows the evolution of radius ratio for two sintering pressures (0.1 and $10^{-4} \mathrm{MPa}$ ) (Clarinval et al., 2004).

The small difference of shrinkage (about $0.5 \%$ ) between sintering with low pressure $\left(10^{-4} \mathrm{MPa}\right)$ and sintering with atmospheric pressure $(0.1 \mathrm{MPa})$ is due to the small number of closed off pores at this stage of sintering.

In general, the volume contained in small (below equilibrium size) pores is considerably smaller than the volume

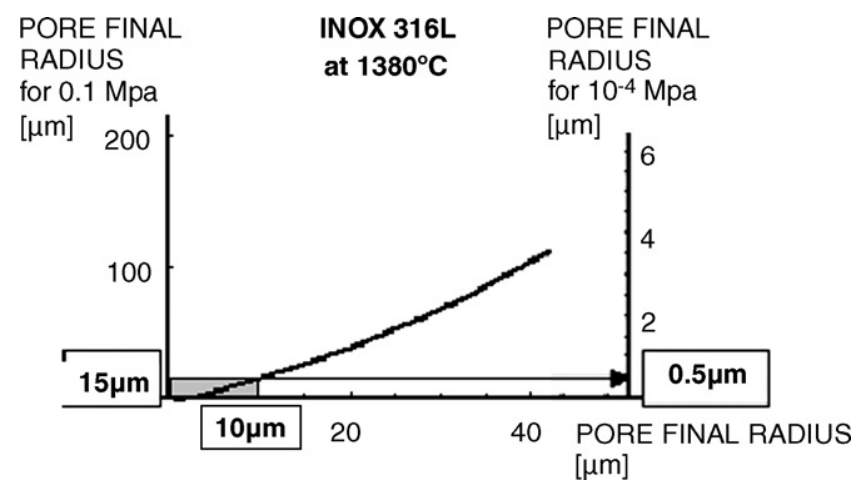

Fig. 2 - Evolution of radius ratio of pores for two sintering pressures. 


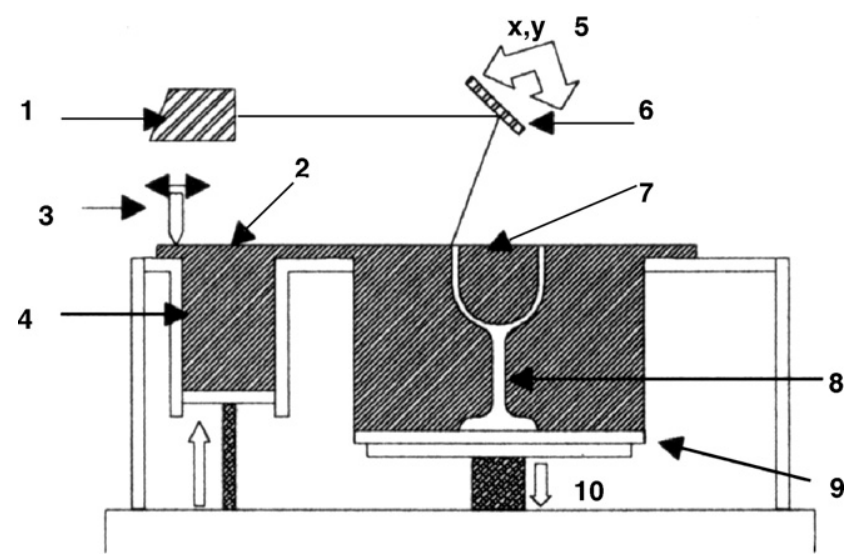

Fig. 3 - Optoform principle: 1, UV laser; 2, paste supply; 3 , recoater including a blade and 2 rotating rods; 4 , paste tank; 5, XY rotation; 6, mirror; 7, photosensitive paste; 8 , polymerized prototype; 9 , building platform; $10, Z$ control.

contained in large (above equilibrium size) pores. However, since the contraction stress in the very small pores is very high, their shrinkage rate will be very rapid compared with the large growth rate of the pores. Even though the total volume of small pores is small, the net change in volume during the early stages of sintering is shrinkage. As soon as the rate of small pore shrinkage slows down, the net change in volume will be due to expansion because the influence of the large pores upon net volume change will predominate due to their relatively large volume. This is what is observed in the volume change of metal pressed powder (Lenel, 1980).

The smaller the porosities are, the faster and better is the sintering. Smaller porosities can be reached by using bimodal powder.

\section{Experimental description}

\subsection{Machine principle and features}

The Optoform is a machine that shapes functional parts from photocurable paste charged with metal powder (Clarinval et al., 2003; Lenel, 1980; Clarinval et al., 2004), ceramic powder (Hinczewski, 2002; Delmotte et al., 2002; Delmotte et al., 2003; Hinczewski et al., 1998; Bertsch et al., 2004; Doreau et al., 2000), elastomeric material (Clarinval and Carrus, in press) or any other material. The only condition constraints of the paste are a good layering process (no deformation due to gravity) and a sufficient polymerization according to the thickness of layers. The paste is applied in fine layers and is locally solidified by a 400 or $800 \mathrm{~mW}$ UV laser beam driven by mirror. The feeder system brings the paste material to a dual-blade recoater moving this roll onto previous layer. The layer thickness may vary between 20 and $200 \mu \mathrm{m}$ depending on the transparency and the rheological properties of the material (Fig. 3).

Maximal dimensions of parts can reach $250 \mathrm{~mm} \times 350 \mathrm{~mm} \times 500 \mathrm{~mm}$ for a maximal building speed of $25 \mathrm{~mm} / \mathrm{h}$ (Dormal, 2000).

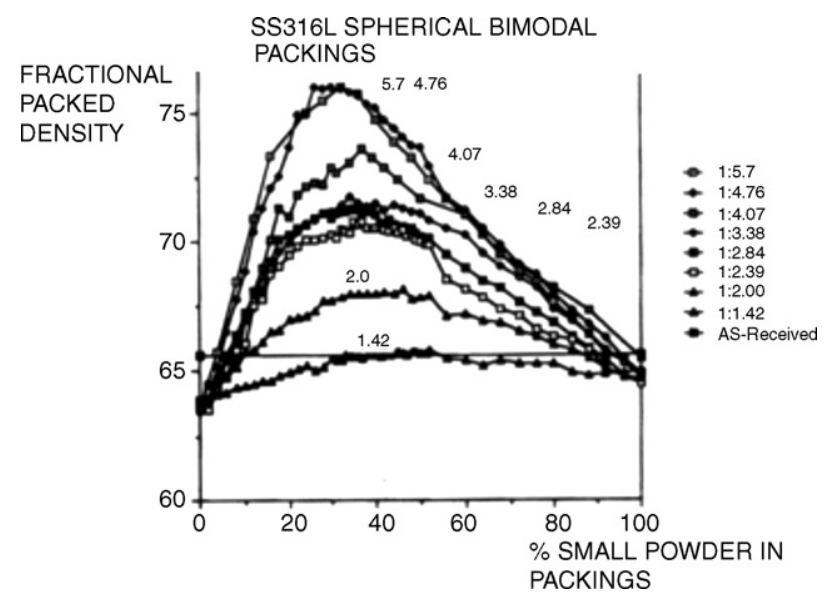

Fig. 4 - Experimental results showing effects of size ratio and composition on packing (Li and Funkenbusch, 1992).

\subsection{Material description}

According to the modelization, some modifications are going to be applied to improve mechanical characteristics.

\subsubsection{Modifications of the paste}

The paste composition comprises

- a solidifiable binding agent comprised of at least one polymerized resin, with viscosity of less than $4 \mathrm{Pas}$, measured at $25^{\circ} \mathrm{C}$;

- at least one photosensitive initiator, in a concentration greater than about $0.1 \%$ with respect to the mass of the resin;

- a bimodal mixture in nature of metal powder; the said mixture having a volumetric concentration greater than $40 \%$ with respect to the composition (Hinczewski, 2002).

Modifications of the paste must be made according to Optoform process.

Bimodal powder that has a high fractional packing density (cf. Fig. 4) is used to have smaller pore sizes in the pressed powder. These small pores should, according to the modelization, reduce final porosities and increase sintering speed. With higher fractional packing density, contacts between grains increase and strengthen the material, although the densification is not complete.

In using a paste charged with $59 \%$ of bimodal metal powder, the new rheology of the paste makes it possible to automate the Optoform process by improving the spreading without using thixotropics additives.

The bimodal proportion will be determined according to the opacity phenomenon. The bimodal powder must not be too pressed otherwise the layer becomes opaque to the UV laser.

If the opacity of the layer is too high, only surface polymerization will occur without latching on layers. Different proportions of small particles in the bimodal powder $(10,15$ and $20 \%$ ) were tested. For a grain size ratio of 2.5 and layers of $75 \mu \mathrm{m}$ thickness, the maximal proportion of small particles 
Table 1 - Characteristics of debinding cycle used by: 1, KUL; 2, Metal Inject SA

\begin{tabular}{llccc} 
No. cycle & Atmosphere & Temperature $\left({ }^{\circ} \mathrm{C}\right)$ & Number of stages & Heat rate $\left({ }^{\circ} \mathrm{C} / \mathrm{min}\right)$ \\
\hline 1 & $30 \% \mathrm{H}_{2}$ & 500 & 2 & 0.2 \\
2 & $100 \% \mathrm{H}_{2}$ & 940 & 2 & $0.4-1.3$ \\
\hline
\end{tabular}

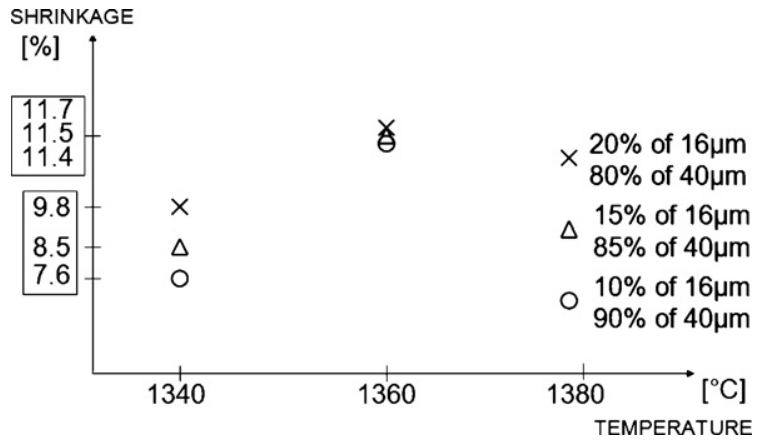

Fig. 5 - Results of shrinkage with different compositions of bimodal powder for different sintering temperatures.

avoiding opacity is $20 \%$. This grain size ratio was obtained by using granulometric distributions centred on 40 and $16 \mu \mathrm{m}$. This ratio is the best compromise between polymerization, cost and packing.

\subsubsection{Optimization of the debinding}

Two debinding cycles coming from $\mathrm{KUL}^{1}$ and Metal Inject SA were tested. The cycle used by Metal Inject SA, which is perfectly adapted to its $\mathrm{MIM}^{2}$ pastes, totally reduces residual carbon of MIM parts. Table 1 shows the main characteristics of these two cycles. We notice that the Metal Inject's cycle is longer at higher temperature than for KUL's cycle.

This high temperature combined with full hydrogen atmosphere increases the following reaction:

$\mathrm{C}+2 \mathrm{H}_{2} \rightarrow \mathrm{CH}_{4}$

\subsubsection{Optimization of the sintering}

Due to the not optimized debinding treatment, the 316L steel contains residual carbon that decreases its melting point. Different sintering temperatures under or equal to the one concerning the $316 \mathrm{~L}\left(1340,1360,1380^{\circ} \mathrm{C}\right)$ were tested to observe the difference in mechanical characteristics between the three bimodal proportions $(10,15$, and $20 \%)$.

\section{Results and discussions}

- Fig. 5 confirms a higher shrinkage for a more packed down bimodal powder. No results are given for $1380^{\circ} \mathrm{C}$ because of the melting that deforms parts.

- The debinding cycle is insufficiently optimized for Optoform's paste. With the MIM's debinding cycle, we have reached a residual carbon of $0.44 \%$, which is higher than required carbon of $316 \mathrm{~L}$ stainless steel: $0.03 \%$. The inox $316 \mathrm{~L}$

\footnotetext{
${ }^{1}$ Katholieke Universiteit Leuven.

2 Metal Injection Moulding.
}

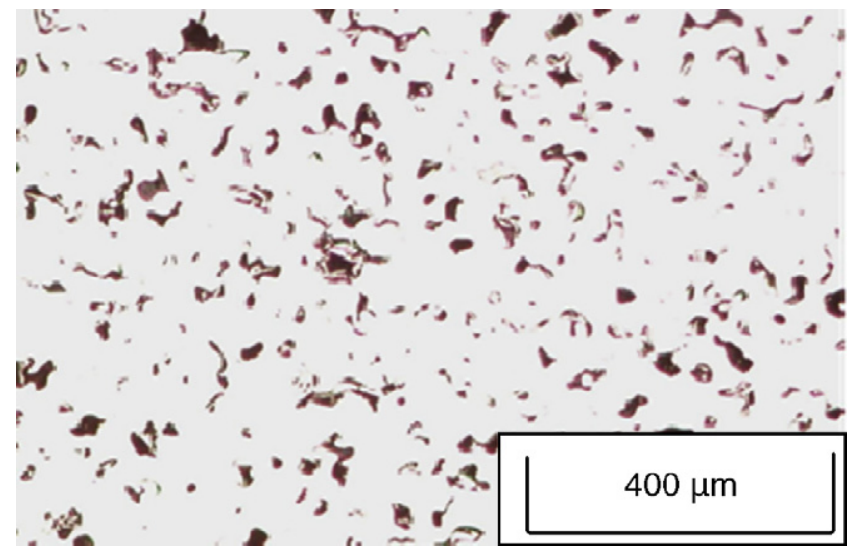

Fig. 6 - Not etched micrograph of inox 316L sintered at $1360^{\circ} \mathrm{C}$. Black colour is porosity and white is sintered inox powder.

stainless steel enriched with carbon modifies the mechanisms of sintering. The maximal temperature that can be reached without melting is $1360^{\circ} \mathrm{C}$. Micrograph in Fig. 6 shows important porosity for an inox $316 \mathrm{~L}$ with $0.28 \%$ of residual carbon at the optimal sintering temperature before melting $\left(1360^{\circ} \mathrm{C}\right)$. Normally, the inox $316 \mathrm{~L}$ sinters very well until a residual porosity smaller than $1 \%$. So this means that debinding cycle is still insufficient to obtain full densification.

- Next graphs (cf. Figs. 7-9) show mechanical characteristics for different compositions of bimodal powder at different sintering temperatures. We notice that the melting begins at $1370^{\circ} \mathrm{C}$.

We can explain the difference observed in mechanical characteristics for different compositions of bimodal powder by the number of contacts between grains. The more packed down in the bimodal powder is, the more contacts (soldering) there will be between grains. So for higher fractional density

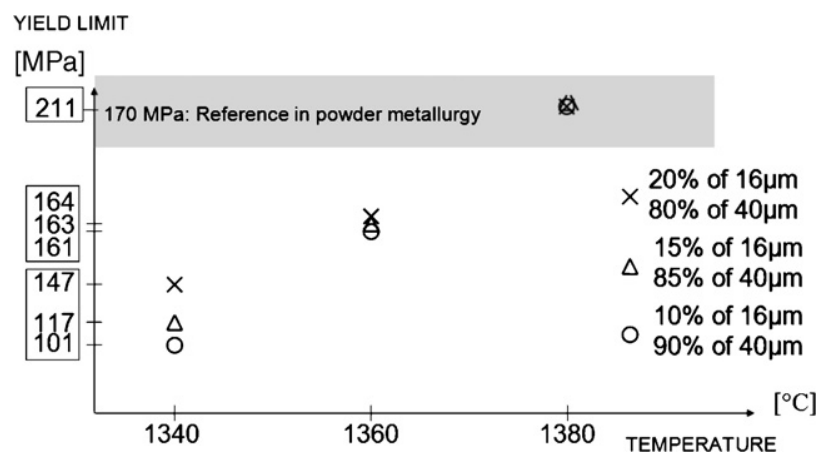

Fig. 7 - Results of yield limit with different compositions of bimodal powder for different temperatures. 


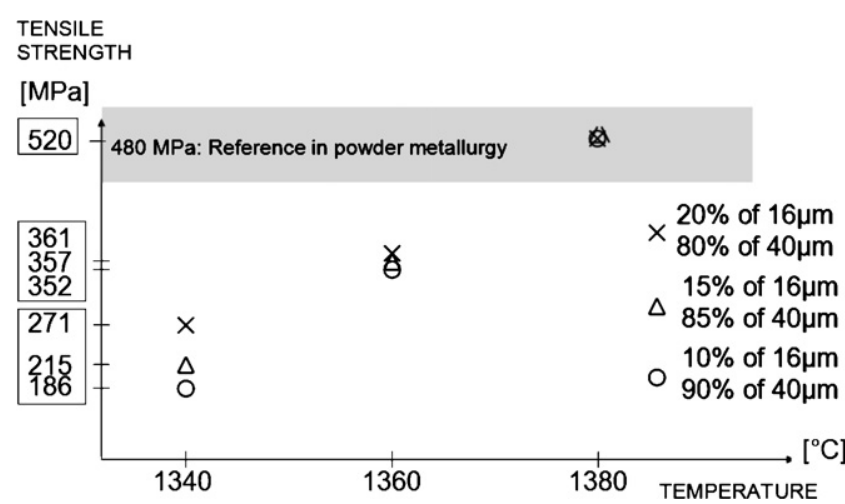

Fig. 8 - Results of tensile strength with different compositions of bimodal powder for different temperatures.

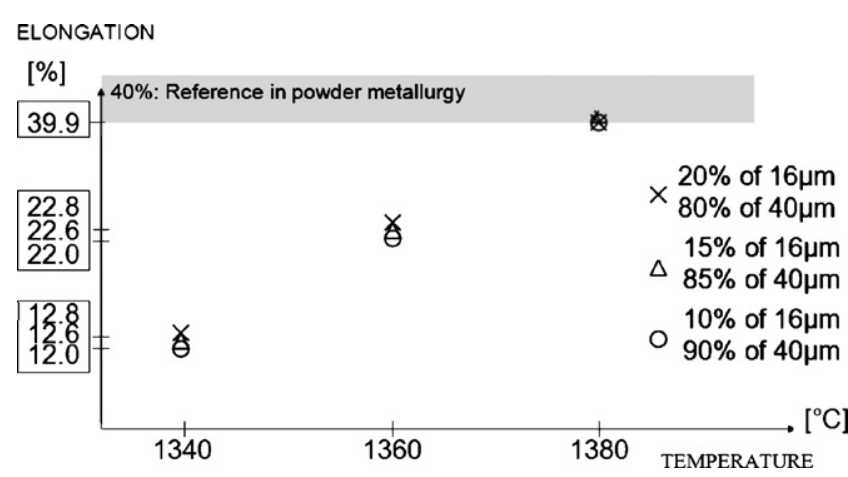

Fig. 9 - Results of elongation with different compositions of bimodal powder for different temperatures.

packing, mechanical characteristics of the material increase. Then we can say that tensile strength and yield limit depend on granulometric proportion.

The convergence of results at $1360^{\circ} \mathrm{C}$ means that optimal sintering temperature is near: contacts between grains increase which involves that granulometric proportion does not intervene anymore.

Concerning the elongation, we notice that it does not depend on granulometric proportion but depends mainly on residual carbon.

\section{Conclusion}

The main problem is the residual carbon that modifies the nature of the metal and so the densification mechanisms. To decrease residual carbon, debinding cycle has to be modified. The diminution of residual carbon leads to a better densification with a higher melting point; but it is still insufficient.

The use of bimodal powder makes it possible to automate the spreading of pastes charged with metal, to have better mechanical characteristics at lower sintering temperature, and so to obtain better surface qualities.

However, the addition of small particles in the bimodal powder is limited by the opacity to the UV laser ( $\max 20 \%$ for a grain size ratio of 2.5 ).
At the end, mechanical characteristics are near the basic metallurgy powder results. Anyway debinding cycle must be improved to reach carbon percentage of $316 \mathrm{~L}$ and have a complete sintering with few porosities. In this way, we will be able to form functional pieces with the Optoform process.

\section{Acknowledgements}

The authors would like to thank Marleen Rombouts and professor Ludo Froyen from the department MTM of KUL. We also would like to thank CYTEC, CRAYVALLEY, CIBA and HÖGANÄS for the delivery of samples. A part of this work was financed by IWT.

\section{REFERENCES}

Allanic, A., Schaeffer, P., in press. Procédé de prototypage permettant l'utilisation de matière pâteuse, Patent FR2790418A1.

Bertsch, A., Jiguet, S., Renaud, P., 2004. Microfabrication of ceramic components by microstereolithography. J. Micromech. Microeng. 14, 203.

Chartier, T., et al., 1997. Tape casting using UV curable binders. J. Eur. Ceram. Soc. 17, 765-771.

Clarinval, A.-M., 2006. Production of Metallic and Ceramic Parts with the Optoform Process. NATO RTO-MP-IST999, Amsterdam.

Clarinval, A-M., Carrus, R., Dormal, T., in press. Photopolymerisable paste composition, Patent EU 02447249.0.

Clarinval, A.-M., Carrus, R., Dormal, T., 2003. Development of materials for Optoform process. In: First International Conference on Research Virtual and Rapid Prototyping, Leiria.

Clarinval, A.-M., Carrus, R., Vaneetveld, G., Noben, J.-C., Dormal, T., 2004. Developpment of functional material for direct manufacturing for ceramic and metal parts by Optoform process. In: First International Conference of Rapid Production, Wowlaw.

Delmotte, K., Erauw, J.-P., Cambier, F., Carrus, R., Clarinval, A.-M., Dormal, T., 2002. Shaping 2. In: Proceeding of the Second International Conference on Shaping of Advance Ceramics, Gent.

Delmotte, K., Erauw, J.-P., Cambier, F., 2003. Ecers Proceeding of the Eighth Conference And Exhibition of Europeen Ceramic Society, Istanbul.

Doreau, F., et al., 2000. Stereolithography for manufacturing ceramic parts. Adv. Eng. Mater. 2 (n 8), 493-496.

Dormal, T., 2000. Optoform: a new process for rapid layer manufacturing based on paste. Rapid Prototyping Tooling Ind. Appl. Newslett. 4, 1-3.

Hinczewski, C., 2002. Metallic filled pastes, Patent US 2002/0176793 A1.

Hinczewski, C., et al., 1998. Ceramic suspensions suitable for stereolithography. J. Eur. Ceram. Soc. 18, 583-590.

Lenel, F.V., 1980. Powder Metallurgy Principles and Applications. Metal Powder Industries Federation (Chapter 9).

Li, E.K.H., Funkenbusch, P.D., 1992. Experimental size ratio and compositional effects on the packing and isostatic pressing of spherical powders. Mater. Sci. Eng. A157, 217-224.

Yukitoshi, K., et al., in press. Resin composition for photofabrication of tridimensional objects, Patent WO 00/59972. 